\title{
Northern dialect evidence for the chronology of the Great Vowel Shift
}

\author{
Hilary Prichard* \\ University of Pennsylvania
}

This paper demonstrates how the tools of dialect geography may fruitfully lend a new perspective to historical data in order to address the lingering questions left by previous analyses. A geographic examination of Survey of English Dialects data provides evidence in favor of a push-chain analysis of the Great Vowel Shift, in which the Middle English high-mid long vowels raised before the high long vowels were diphthongized. It is also demonstrated that the so-called "irregular" dialect outcomes, which have previously been cited as evidence for a lack of unity of the Great Vowel Shift, are no longer problematic when viewed in the light of a theory of dialect contact, and can in fact refine our understanding of the chronology and geographic extent of the shift itself.

\section{Introduction}

After over a century of debate, the chronology of the Great Vowel Shift (GVS) is still unclear. This paper represents a departure from past lines of argumentation in its approach to the questions surrounding the GVS; rather than arguing purely from theory, or from the evidence of a few isolated data points, the geographic patterns of dialect data from across the entire north of England are examined here with the goal of testing previous hypotheses of the GVS chronology. Applying arguments from modern variationist studies to historical data lends a new perspective to the questions surrounding this sound change. The results are twofold: Broadly speaking, this research presents evidence that unexpected dialect outcomes need not challenge a unified chain shift model of large-scale sound change, while in particular, the data presented here supports a push-chain analysis of the GVS, à la Luick (1896).

Over the course of the past century, countless scholars have weighed in on questions of the Great Vowel Shift's cause, chronology, and phonological mechanism, thus far failing to reach a consensus on any of these points. If there is one point that these scholars do agree upon, it is that, outside of the standard southern dialects of England, the modern reflexes of the Middle English (ME) long vowels are not always what we would expect to find as the outcome of the GVS; in particular, the most northern parts of England still retain the monophthongal Middle English $\bar{u}$ in words of the MOUTH class. Models of the GVS constructed by scholars from Luick (1896), to Stockwell and Minkova (1988), Johnston (1992), and Smith (1996, 2007),

\footnotetext{
*Address for Correspondence: Hilary Prichard, Department of Linguistics, University of Pennsylvania, Philadelphia, PA 19104-6305

(Email: hilaryp@ling.upenn.edu)
}

have relied heavily upon differing interpretations of these nonstandard dialect outcomes. While Luick posited a unified chain shift model of the GVS in which this unshifted ME $\bar{u}$ found in some northern dialects was seen as the key to understanding the ordering of the changes, some later scholars have tended to interpret the dialect data as posing a problem for a unified model of the shift (e.g., Stockwell \& Minkova, 1988; Smith, 2007). Their general contention is that these nonstandard reflexes are the exceptions which disprove the rule, and they have accordingly supplied alternate theories which do not require all the different changes involved in the GVS to be dependent upon one another.

The underlying assumption behind these objections seems to be that, in order for the GVS to be considered a unified phenomenon, it must have proceeded via the same mechanism in every dialect where shifted forms are found. However, we assume that there are several different possible mechanisms of change. Variationist studies have identified diverse changes which are argued to be the product of such mechanisms as levelling, or lexical diffusion, rather than regular Neogrammarian sound change. This paper is based in a framework proposed by Labov (2007), which views sound change as the result of two distinct mechanisms, transmission and diffusion. Within this framework, we will explore whether the nonstandard northern dialect forms may be viewed as the unsurprising product of diffusion. This is a point previously raised by Dinkin:

Stockwell and Minkova's citing of regions of England in which some GVS shifts took place but not others does not in principle vitiate the traditional model of chain shifting-the conclusion is merely that those may be regions to which 
the GVS diffused, rather than ones where it originated as a chain shift. (2012:755)

The distinction between transmission and diffusion will be further discussed below, but the key idea is that highly structured changes-such as the GVS-retain their internal structure when they are the product of transmission, but break down and tend to show irregularities when they are diffused. Given this, an examination of the dialect data should be able to reveal where the GVS was transmitted as a highly structured chain shift, and where diffusion has resulted in a breakdown of this structure.

\section{Background}

\subsection{The Great Vowel Shift Debate}

The ongoing debate surrounding the status of the Great Vowel Shift originated with the work of Luick (1896) and Jespersen (1909). While it was Luick's work which in essence sparked a century-long debate, Jespersen's conception of the shift has since become more well-known and widely accepted (see, e.g., Johnston, 1992; Lass, 1976:57; Stockwell \& Minkova, 1988). Both saw the shift as a series of connected, interdependent changes, but differed in their view of the order in which the changes took place chronologically. Jespersen, pointing to parallel changes in other Germanic languages, posited what is now termed a pull- or drag-chain model, in which the initial event which caused the shift was the diphthongization of the high vowels (Figure 1a).

In contrast, Luick argued that the mid vowels $\bar{e}$ and $\bar{o}$ initiated the shift by raising and displacing the high vowels, a push-chain. The crux of Luick's argument rests on the fact that certain modern English dialects retain ME $\bar{u}$ while still showing other parts of the shift. He took this as evidence that the shift cannot have been initiated by the high vowels, since such a model cannot account for why $\bar{u}$ only diphthongized in some dialects and not others. He demonstrated that a push-chain model better accounts for this fact; the reason $\bar{u}$ did not shift in these dialects is that they had undergone an earlier change in which ME $\bar{o}$ was fronted (Figure 1b). Under a push-chain model, this prior $\bar{o}$-fronting effectively (a)

$\begin{aligned} \text { ai } \leftarrow \mathrm{i}: & \mathrm{u}: \rightarrow \text { au } \\ \uparrow & \uparrow \\ \mathrm{e}: & \mathrm{o}: \\ \uparrow & \uparrow \\ \varepsilon: & 0: \\ \uparrow & \\ \mathrm{a}: & \end{aligned}$

(b)

\begin{tabular}{|c|c|}
\hline$\leftarrow \mathrm{i}:$ & $\mathrm{y}: \quad \mathrm{u}$ \\
\hline$\uparrow$ & $\uparrow$ \\
\hline e: & $\varnothing: \leftarrow 0$ \\
\hline$\uparrow$ & \\
\hline$\varepsilon:$ & \\
\hline$\uparrow$ & \\
\hline$a:$ & \\
\hline
\end{tabular}

Figure 1. The Great Vowel Shift (a) and the GVS in the north (b). prevented the back vowels from participating in the chain shift by not supplying the pressure necessary for $\bar{u}$ to diphthongize.

Much work on the GVS has followed Luick and Jespersen in positing that the shift proceeded as a coherent, "unitary" change, in which the back and front vowel shifts are necessarily related and the individual front and back vowel changes are structurally dependent upon one another. Such work has been united in attempting to explain the underlying phonological mechanism of the shift from this basic premise, while differing in whether the individual changes are chronologically ordered or occurred simultaneously. Indeed, several scholars have presented analyses of the GVS using one or more structured rules (e.g., Chomsky \& Halle's 1968:256 ordered exchange rules, Carter's 1975 abstract schema, Lass's 1976 rules and metarules), which, depending upon their implementation, may be interpreted as giving rise to either simultaneous or ordered changes. In spite of these analyses, it is not obvious that the GVS was ever implemented as a synchronic rule, or that the structured rules of Chomsky and Halle, for example, should be interpreted as such. Furthermore, the simultaneity argument may be driven more by the needs of phonological theory than the available evidence (see Lass, 1976:65). This argument hinges on the idea that any temporally-ordered changes would necessarily have led to vowel class mergers rather than the overall shift which did occur (Stockwell \& Minkova, 1988:366). However, real-time studies of current chain shifts in progress have demonstrated that such shifts need not lead to merger (e.g., Labov et al., 2006). Lass (1976:71) argues that this type of change may even be accommodated in a rule-based approach by stipulating a "no collapse" output condition.

While the proponents of such rule-based accounts have had to redefine what it means for a shift to be "unitary" when no single traditional rule can satisfactorily account for all of the changes involved, they have still largely sought to preserve the idea of unity and coherence in their analyses of the GVS; Lass (1992:148) in particular defends Luick's concept of innere Zusammenhang (internal coherence), and sees the traditional conception of the GVS as a pattern "too valuable to discard." By contrast, a significant minority of scholars do not agree that the unitary status of the GVS is above question, calling attention to irregularities in the dialect data in order to challenge the idea that the shift was in any sense unitary. Stockwell and Minkova (1988) put forth a scathing review of previous work, concluding that the GVS is "the linguist's creation through hindsight." Their objection which is most relevant here is what they term "the dialect problem." Briefly, their contention is that " $[t]$ he vowel shift did not proceed along the same lines in the dialects as it is assumed to have done in London," and 
the wide range of apparently irregular ${ }^{1}$ outcomes of the shift found in the dialect data is evidence against a unitary chain shift model of the GVS. Stockwell and Minkova are not the only scholars who have pointed out irregularities in the dialect data; Western (1912) and Boisson (1982) have both cited examples which seem problematic for a unitary model of the GVS. ${ }^{2}$ As we shall see below, it is irrefutably the case that the Middle English vowel reflexes are different in the north than they are in the south; however, this fact does not necessarily rule out a unified account.

A rather different take on the question of the status of the GVS in the north comes in the form of Smith's (2007) contention that the GVS, as it is usually conceived, did not happen in the north at all. Rather, he argues for two separate shifts - a Southern Shift (the GVS as we know it), and a separate Northern Shift (which was in essence just the front half of the GVS) - noting that,

[I]t is worth recalling that similar outcomes in the history of sounds can often derive from diverse origins. It is thus quite possible that the northern and southern shifts, though in some ways similar, could be differently triggered [...]. (Smith, 2007:140)

This is certainly a fair point, and would be interesting if it could be proven; however, Smith's argument for the independent triggering of these two shifts is at best weakly supported by the sources he cites. It is equally true, as demonstrated below, that these similar outcomes can be explained as deriving from the same source; why then posit two shifts, when one will do the job?

\subsection{A Variationist Perspective}

Labov (2007) proposes a resolution to the tensions between the family tree and wave models of linguistic change in the form of two different mechanisms of change. The first, transmission, is linguistic descent of the type modeled by the family tree; in its prototypical form, it consists of faithful transmission from generation to generation via first language acquisition in children. By contrast, diffusion occurs in contact situations between adults, and is thus expected to show more irregular outcomes than transmission. Labov demonstrates this distinction clearly in his examination of the difference between the regular outcomes of transmission of the Northern Cities Shift throughout the Inland North dialect area versus irregularities resulting from the diffusion of this chain shift along the St. Louis corridor. Further work by Dinkin (2012) on the diffusion of the Northern Cities Shift in New York supports the idea that when chain shifts diffuse, the structural relationships cease to hold, resulting in irregularities.
The research presented here will investigate whether the GVS dialect irregularities noted in the literature may similarly be explained as the result of the diffusion of a unitary chain shift. In particular, the maps presented below are analyzed in terms of the geographic relationships between the modern reflexes of the $\mathrm{ME}$ vowels, drawing on the common isogloss relationsbundling, complementation, and nesting-found in dialect geography. As the GVS is traditionally conceived of as a chain shift, the nesting relationship, in which "the spatial distribution of one feature is contained entirely within that of another, establishing an implicational relationship" (Labov et al., 2006:44), will be of particular importance.

\section{Data \& Methods}

This project makes use of data taken from Eduard Kolb's 1966 work, the Linguistic Atlas of England: Phonological Atlas of the Northern Region (PANR). The data for this atlas was collected between 1950 and 1961, as part of the Survey of English Dialects (SED) project. Kolb hand-picked raw data from the SED interviews in order to present a cohesive picture of the patterns of variation in northern phonology. In the PANR, SED data is presented as a series of maps, which each display the phonetic realization of a single lexical item in the eighty different northern SED locales. ${ }^{3}$ The maps are organized into groups based on the Middle English vowel class of the word, making the SED data more readily accessible for the purposes of this project. The data is drawn from the six traditional northern counties in addition to northern Lincolnshire and the Isle of Man. The former is not typically thought of as part of the north, but is included by Kolb for linguistic reasons. As Wells notes,

'Northern' in this sense might more precisely be glossed 'midlands or northern'. We cross from the south to the linguistic north at the point where we pass the northern limits (in broad local accents) of the FOOT-STRUT Split and of ватH Broadening. (1982:II.349)

This linguistic line often does not correspond perfectly with the popular conception of the north, as revealed, for example, by the work of perceptual dialectologists (see e.g., Montgomery, 2007). The Isle of Man is not included in this analysis, due to its distinct linguistic history.

The SED used traditional data collection methods: Fieldworkers hand-recorded close transcriptions of informants' responses to a standard questionnaire, which contained over 1000 questions and typically took at least four days to complete. The recording sites are all small rural towns, with the exception of York 


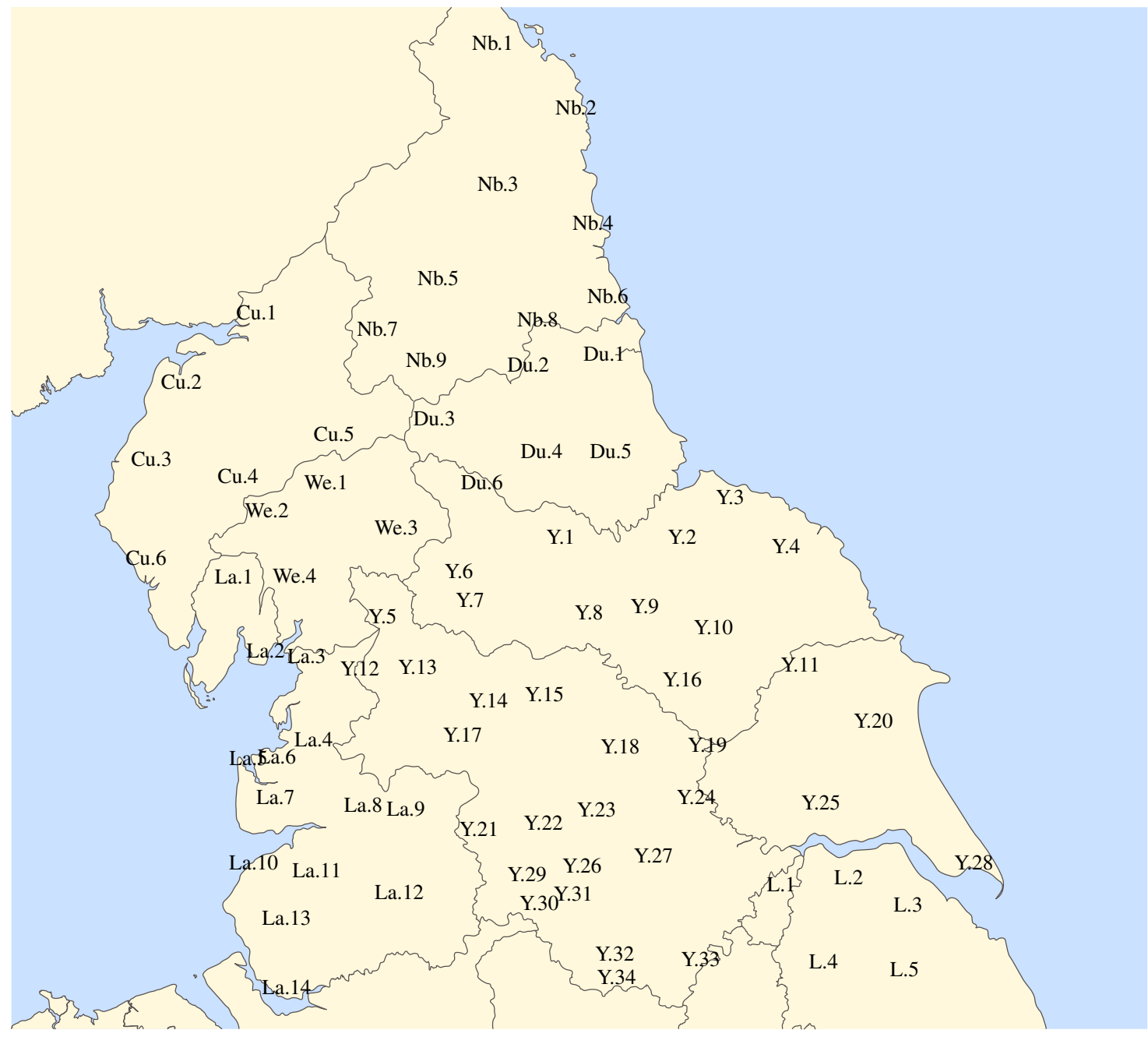

Map 1. PANR base map.

and Leeds. Map 1 is a base map of the towns included in the atlas, with historical county borders for reference. SED numbers are given, and the online and SVG versions of these maps also display the town names.

Informants were chosen on the basis of how well they represented the local traditional dialect, and were typically male, aged 60 or above, and engaged in agricultural work (Orton, 1962). Each point on the map represents the responses of anywhere from 1-5 informants. In most cases only one variant per word was recorded in each location; however, in the few cases where different variants were present, the additional variants were usually included either as an additional point or diacritic on the map, or listed in a key if they were considered by Kolb (1966) to be unusual or otherwise unrepresentative. For the purposes of this project, only the variants recorded on each map itself are used, as they are assumed to be the most reliable data.

This paper is written very much in the spirit of the original work of Eduard Kolb (1966) upon which it is based, in that it recognizes that a carefully-selected subset of the available data can in itself be enlightening. Thus, of the considerable amount of data contained in the PANR, thirty-three of the ME long vowel words were transferred to digital format, corresponding to the modern PRICE, FLEECE, FACE, MOUTH, GOOSE, and GOAT classes (Wells, 1982). A limited amount of re-categorization was done, the goal being to reduce the number of keyed variants to a manageable amount by eliminating phonetic minutia, in the hopes of attaining a clearer identification of the broad phonological patterns. For example, diacritics indicating fine differences in vowel quality (e.g., ạ', ${ }^{\prime}$ ) were ignored, and variants with the same nucleus but superscripted onor off-glides which differ slightly in quality are generally mapped together (e.g., ${ }^{\circ} \mathrm{u}:{ }^{\circ} \mathrm{u}$ :).

There have been several past efforts to map the SED vowel data in a more theoretically interesting way than previous lexical atlases, and each has wrestled with the problem of representing multidimensional data in traditional, often black-and-white, print media. Kolb 


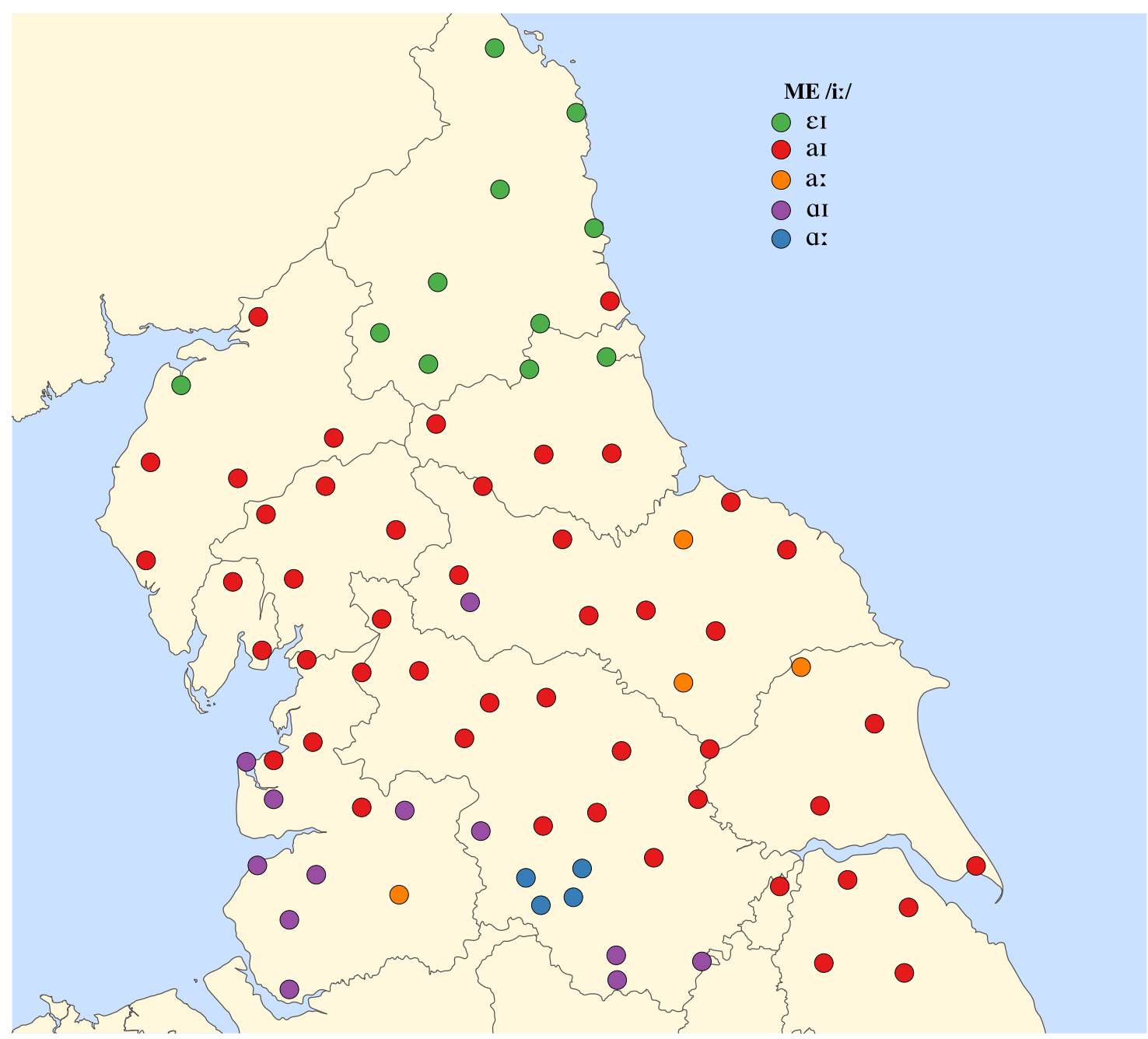

Map 2. Reflexes of ME $\bar{l}$.

(1966) chose to create a separate map for each word, demonstrating in rich detail the extent of the phonetic variation in each, but making it difficult to arrive at phonological generalizations across an entire vowel class. Anderson (1987) took the opposite approach, mapping the geographic distribution of each reflex of a vowel class. This technique makes it easier to see the distribution of any one variant of interest but creates difficulty in identifying the geographic relationships between different variants. Other notable approaches include Ogura's (1987) work on the role of lexical diffusion in the spread of the GVS, and Labov's (1994:476ff) review thereof.

Thanks to the new possibilities provided by online publication, we no longer have to limit our examination of the SED data to one dimension at a time. The mapping method used here affords a more comprehensive view of the vowel system, as well as closer scrutiny of the patterns of diffusion, including previously obscured nesting effects of the variants. Each map displays all of the variants found in an entire vowel class; the points are color-coded according to which variant was the most frequent in the words sampled, and the tooltips (which are displayed when hovering the mouse over any point) contain a list of every other variant found at that location. ${ }^{4}$ In this way it is possible to achieve a wider view of the geographic relationships between the most common reflexes of each Middle English vowel class, without losing the rich phonetic detail and lexical differences in the process.

\section{Results}

The thirty-three digitized PANR words are presented here in a series of nine maps, reflecting Kolb's ME long vowel categories: $\bar{\imath}, \bar{e}, \bar{\varepsilon}_{1}, \bar{\varepsilon}_{2}, \bar{a}, \bar{u}, \bar{o}, \bar{\jmath}_{1}$, and $\bar{\nu}_{2}$. The vowels $\bar{\varepsilon}$ and $\bar{\jmath}$ are both divided into two categories, indicated by subscripts, due to their being reflexes of different Old/Early Middle English etymological classes. We will first examine the relatively unproblematic front 


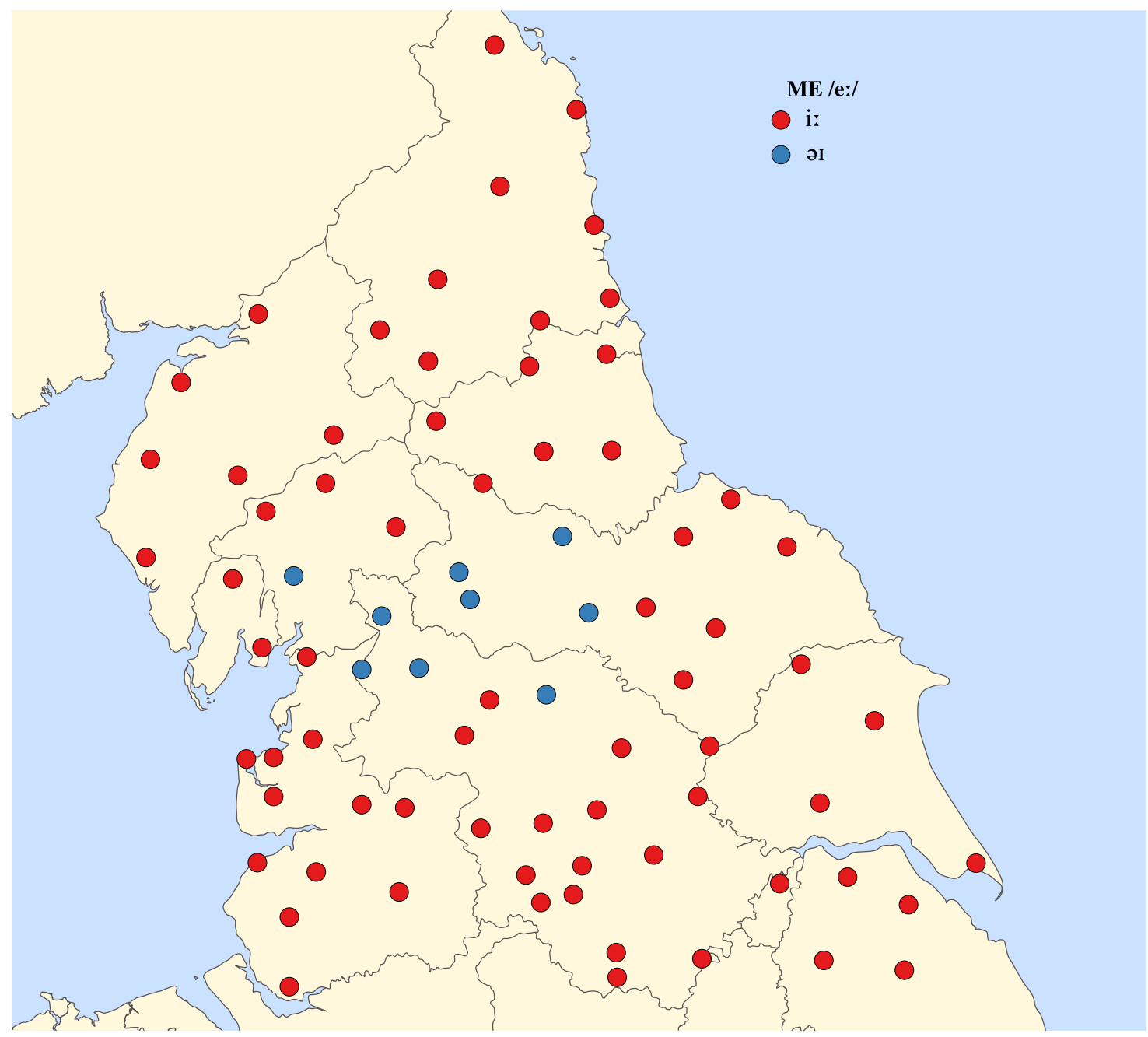

Map 3. Reflexes of ME $\bar{e}$.

vowels and consider the evidence they provide for a specific chronology of the GVS, before turning to the more controversial and irregular back vowel reflexes.

\subsection{The Front Vowels}

Map 2 shows the most common reflexes of $\mathrm{ME} \bar{\imath}$ in the following lexical items, which are part of the modern PRICE class: sky, Friday, time, knife, and writing. It should be noted that this vowel class is subject to the Scottish Vowel Length Rule (SVLR) in Northumberland and Tyneside, unlike other parts of England. Thus, in these locations all words in this set except for sky should show the short allophone predicted by the SVLR. Milroy (1996:214) reports that this short allophone is "regionally marked and has a high-mid nucleus near [ei] rather than the mid (central) nucleus usually described for the SVLR."

This map shows a clear progression of the change from [i:] > [ar] from south to north; the expected reflex [ar] is found in the northeast, and further advanced forms [aI, a:, a:] are found in the south-central area. In Northumberland we find the expected SVLR variant, [عI], in all words except $s k y$, which shows [ar]. Wells (1982:I.149-150) notes that back [aI] variants are characteristic of the urban south, while glide weakening or monophthongization is prevalent in Manchester and Leeds; it is indeed in the southwest Manchester area that we see the heaviest concentration of monophthongal forms in Map 2.

Based on this map, it appears safe to say that the diphthongization of $\mathrm{ME} \bar{\imath}$ has gone to completion in the north; there are no pre-shift or partially-shifted reflexes to be found in this data. The shift is furthest advanced in the southernmost counties, exactly what we would expect to see from a change which is generally thought to have originated in the south. ${ }^{5}$

Moving on to the next vowel involved in the front half of the GVS, Map 3 shows the most common reflexes of ME $\bar{e}$ (modern FLEECE class) in the following lexical 


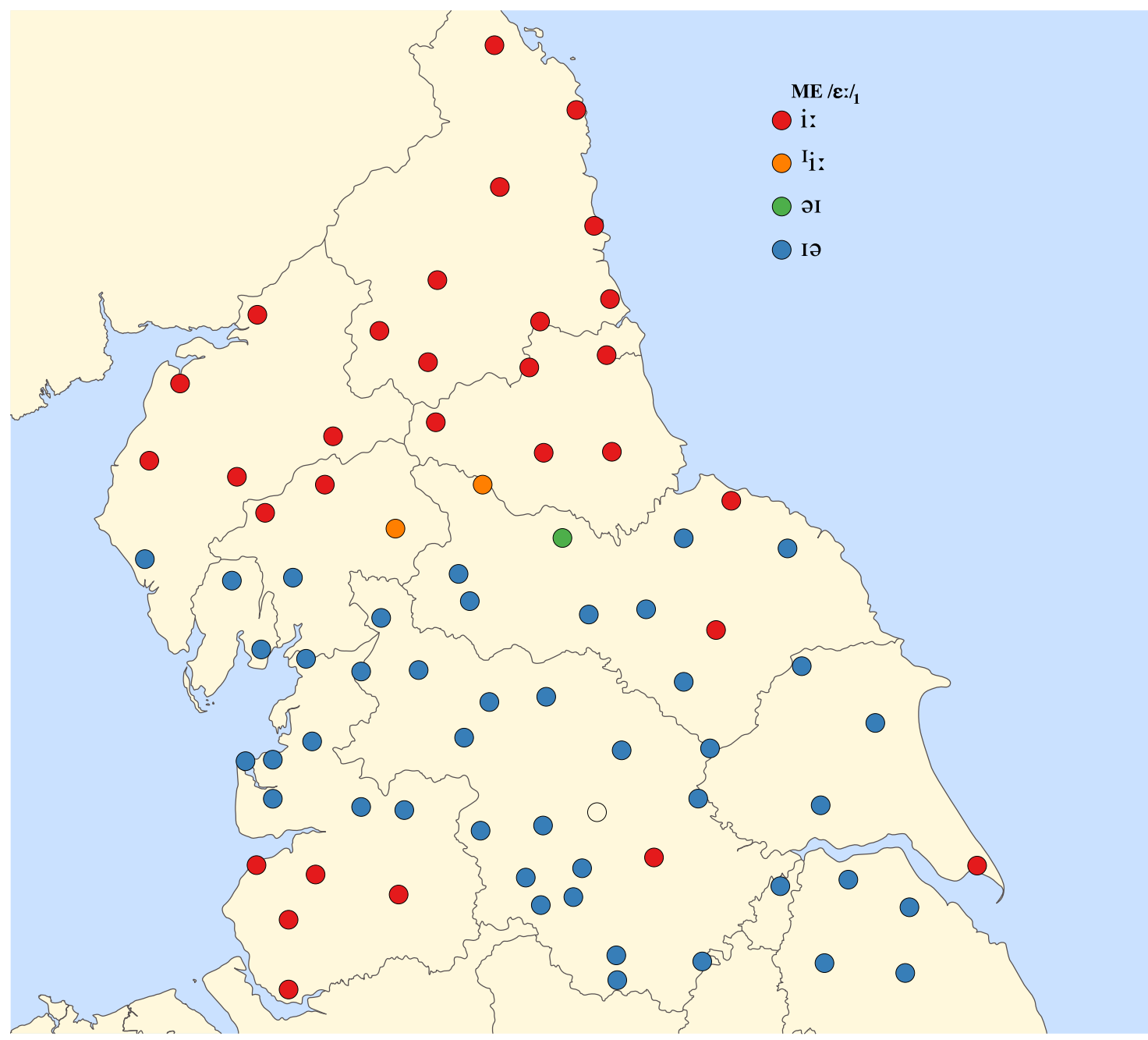

Map 4. Reflexes of ME $\bar{\varepsilon}_{1}$.

items: three, wheel, geese, and sheep. This is by far the most uniform map reproduced here, from which it is clear that the $\bar{e}>[\mathrm{i}$ : $]$ shift has gone to completion. The only part of the north which does not have [i:] as the most frequent reflex is the patch of [әг] in the Yorkshire Dales. As the Dales are a mountainous and sparsely populated area, it is tempting to identify this as a relic area; however, [əг] is not terribly likely to be an intermediate step between [e:] and [i:]. Fortunately, Lass (1976:90ff) demonstrates how such a reflex might be analyzed as innovative, taking Dentdale, Yorkshire as a case study. This particular form is indeed more plausible as a further development of the shift to [i:], since as Dobson (1968:659) observes, the shift from [i:] > [ii] > [əi] (which he proposes as the trajectory for ME $\bar{l}$ ) is attested in more modern Cockney and Australian varieties. Thus while there may be a handful of older forms still in use throughout the north (possible candidates include the [eI] in three found in Du4 and Du5), this change has uniformly gone to completion.
Map 4 shows the outcomes of $\mathrm{ME} \bar{\varepsilon}_{1}$ in the words team and wheat. This vowel class derives from Old English (OE) $\bar{x}, \bar{e} a$ and was raised first to [e:] via the GVS, and later to [i:] via the $18^{\text {th }}$ century FLEECE merger. Wells (1982: I.195) notes that this later change didn't happen everywhere, and pre-merger pronunciations are found in much of the north. On the whole it would appear that the $[\varepsilon:]>[e:]>[i:]$ shift did happen throughout the far north and southwest; the glaring exception is the wide band of locations where this vowel is realized as an ingliding [ı]. Anderson (1987:65) says of this reflex, "It is reasonable to regard this type as representing the oldest vernacular type to have developed from ME / $/$ :/." That being the case, it is difficult to explain why the far north does not share this older type, but rather has the fully-shifted pattern. Anderson's (1987) suggestion that this vowel was "caught" between ME $\bar{a}$, which raised early, and ME $\bar{e}$, which raised slowly, is confusing at best, and does not explain how this pressure would have caused ME $\bar{\varepsilon}$ to raise in the far north. 


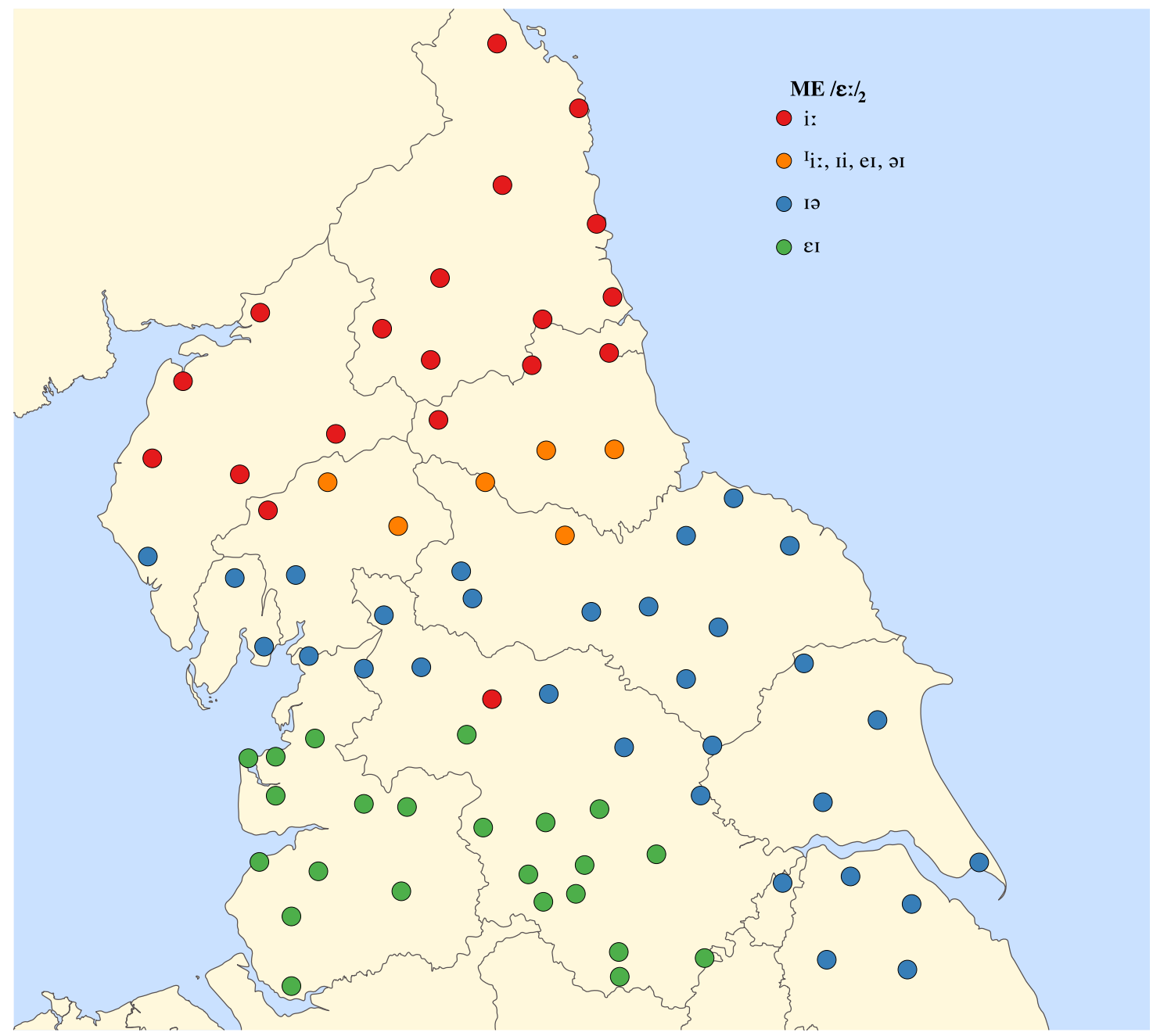

Map 5. Reflexes of ME $\bar{\varepsilon}_{2}$.

Map 5 meanwhile shows the outcomes of $\operatorname{ME} \bar{\varepsilon}_{2}$, which is derived from OE/early ME $\breve{e}$ after Open Syllable Lengthening (OSL). In most English dialects, this vowel followed the same path as $\bar{\varepsilon}_{1}$ and also finished as part of the modern FLEECE class. Indeed, we see rather similar outcomes between the two classes, save for the patch of $[\varepsilon I]$ in the southwest found here. This reflex occurs in the part of England where $\mathrm{ME} \bar{\varepsilon}_{2}$ did not merge with $\mathrm{ME} \bar{\varepsilon}_{1}$, but rather remained distinct, developing an upgliding diphthong (Anderson, 1987:82). Thus Maps 4 and 5 are identical for the locales where these two [ $\varepsilon:]$ classes merged but show a contrast for most of Lancashire and south Yorkshire, where they did not. This data comes from the words eat, steal, and speaks (from OE etan, stelan, specan, subject to OSL).

Map 6 shows the last vowel involved in the front half of the GVS, ME $\bar{a}$. The lexical items this map shows are spade, grave, bacon, and gable. The history of this vowel class, the modern FACE class, is somewhat complex. The GVS resulted in $\bar{a}$ raising to $[\varepsilon:]$, which Dobson
(1968:594) says must have begun in the $15^{\text {th }}$ century and progressed first through [æ:]. Thus ME $\bar{a}$ and ai merged in [E:] sometime in the $16^{\text {th }}$ century and continued to raise together (Dobson, 1968:779). By the $17^{\text {th }}$ century, [e:] had already begun to occur, and was standard by the $18^{\text {th }}$ century. The modern [eI] pronunciation dates from around 1800. So in sum, [a: $]>[æ:]>[\varepsilon:]>[\mathrm{e}]>[\mathrm{eI}]$. There is also evidence of an [عə] reflex in northern dialects, attested in Gil (1619), Smith (1568), and Cooper (1685) (quoted in Dobson, 1968:603).

This extended series of changes between ME and Modern English leaves more room for variation in the modern reflexes, and indeed a good deal more variation is seen here. Many points show some variant of the expected [e]-nucleus, but some also appear to be further advanced to an [I]-nucleus, while most do not appear to have undergone the later shift to [eI] at all. Wells (1982:II.357) states that the [eI] form only developed in the midlands and perhaps the urban middle north; if so, this must be a quite recent change, as no trace can be found in this data. 


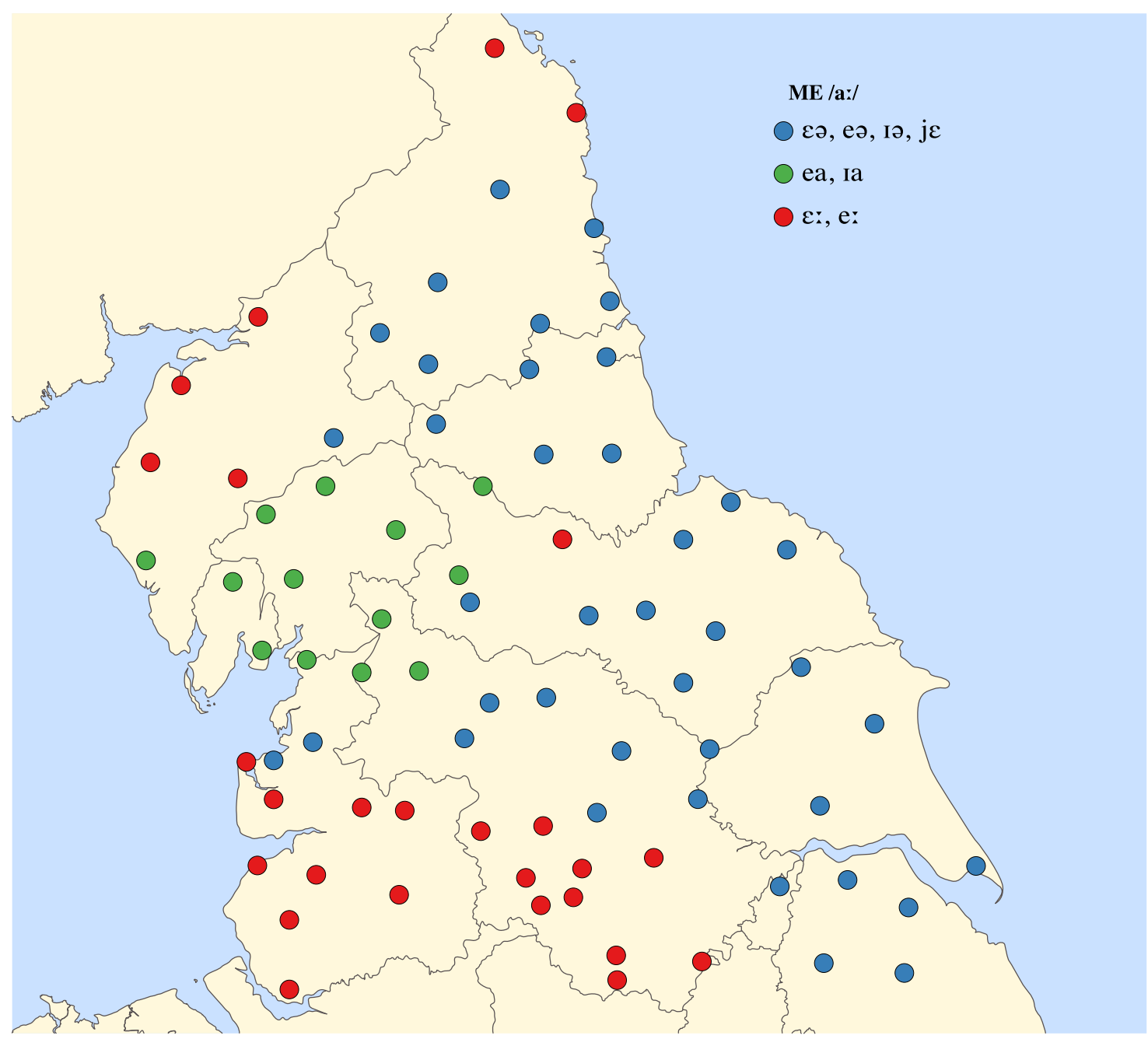

Map 6. Reflexes of ME $\bar{a}$.

On the basis of this map, it is safe to say that the first "step" as it were in the GVS raising of ME $\bar{a}$ did occur throughout the north-there are no locales which retain [a:] or [æ:]. Furthermore, in describing the modern variation for this vowel, Beal (2010:19-20) identifies the ingliding diphthongs found throughout most of the north as "traditional" and observes that they are now largely lost in favor of the more "pan-Northern norm" of monophthongal [e:] or the diphthongal [eI] which is now spreading from Manchester and Liverpool. Indeed, Kerswill (2003) reports a dramatic decline in the use of the traditional [ı] in favor of [e:] among young speakers in Newcastle. This agrees with the pattern in Map 6, where we do indeed see [e:] in the southeast Manchester-Liverpool area, with the traditional ingliding diphthongs dominating the rest of the north.

Thus far, we have seen each piece of the front half of the GVS robustly represented in the north. The shift from $\bar{l}$ to [aI] even showed a small nesting pattern, with the reflexes in the southeast displaying progressively advanced forms (later backing and/or monophthongization changes) nested inside the expected [ar] reflexes to the north and west. Next, the shift from $\bar{e}$ to [i:] is uniformly represented across the entire north, with the exception of the innovative [əI] reflexes in the Yorkshire Dales. The shift from $\bar{\varepsilon}$ to [i:] in both the $\bar{\varepsilon}_{1}$ and $\bar{\varepsilon}_{2}$ classes proceeded as expected in the northernmost and southernmost counties, with the standard [i:] reflex beginning to encroach on the traditional [Іә] form along the north Yorkshire border (see e.g., Du6, Y2). Finally, the shift from $\bar{a}$ to [ $\varepsilon$ : certainly occurred throughout the north, but the region shows a much higher degree of variation in terms of what happened after that initial raising than it did for any of the other front vowel classes.

In terms of chronology, the patterns summarized here tend to support the view that the shift began with the upper half of the vowel system; that is, the raising of $\bar{e}$ and diphthongizing of $\bar{l}$, since these two vowels show the most complete and consistent GVS reflexes. The lower 


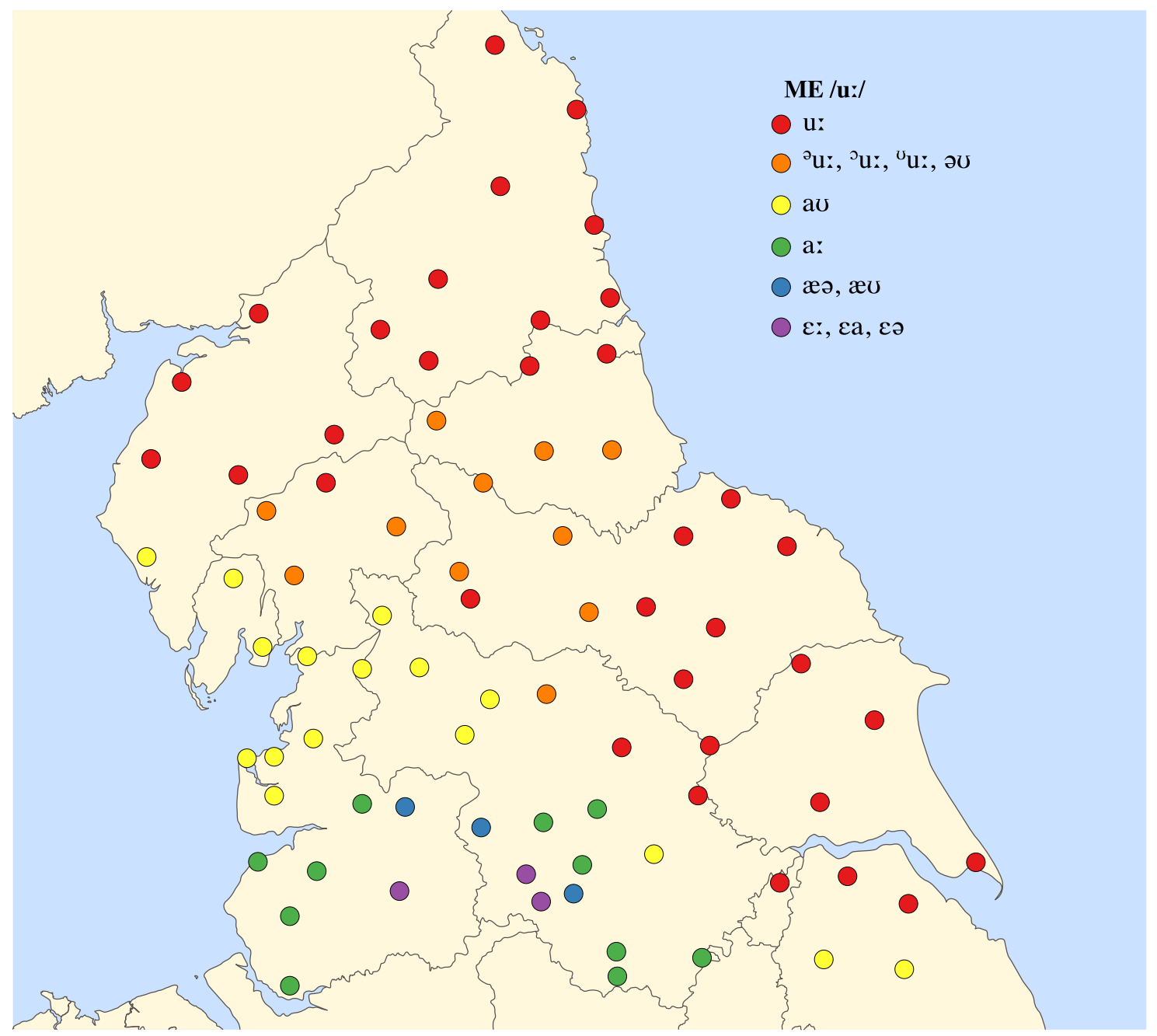

Map 7. Reflexes of ME $\bar{u}$.

vowels $\bar{\varepsilon}$ and $\bar{a}$ also show the expected GVS reflexes, but to a lesser extent as there are large areas of the North which still maintain older forms. Accepting then, for the moment, the Luick/Lass formulation of the GVS as being driven by mid-vowel raising, thus far we have seen no locales which might be described as having an irregular or incomplete form of the shift, leading to the conclusion that these changes are the product of transmission.

\subsection{The Back Vowels}

Map 7 shows the reflexes of the vowel at the heart of this century-long debate: ME $\bar{u}$, the modern MOUTH class. This map is based on the words how, house, clouds, about, and drought. There is a very clear distinction between the [u:]-retaining areas in red and the shifted areas, with a transition zone consisting of points with a small on-glide or a centralized nucleus. Similar to what we saw for ME $\bar{l}_{\text {, }}$ there is also a clear nesting pattern here, with the most advanced forms-[a:], [æu], etc.-clustered in the southwest and fanning out from there. Unlike ME $\bar{\imath}$, there is a large area which retains the older, unshifted $\bar{u}$, encompassing not only Northumberland, but also northern Cumberland and Westmorland, eastern Yorkshire, and part of northern Lincolnshire, roughly north of the Ribble-Humber line. Wells (1982:I.152) identifies the $[æ \sim \varepsilon \sim \mathrm{e}]$ nucleus variants with southern, innovative dialects, and the schwa variants as conservative and rural.

The outcomes of the next back vowel, ME $\bar{o}$, are shown in Map 8. The lexical items used are noon, boots, tooth, and moon, which belong to the modern GOOSE class. Wells (1982:I.185) says, "North of a line running from southern Cumbria to the Humber estuary, the present-day dialectal reflex of Middle English /o:/ is a front vowel, e.g. [gies] goose, while Middle English /u:/ remains monophthongal, e.g. [hu:s] house." The line Wells references is, of course, the Ribble-Humber line, an old and persistent bundle of isoglosses 


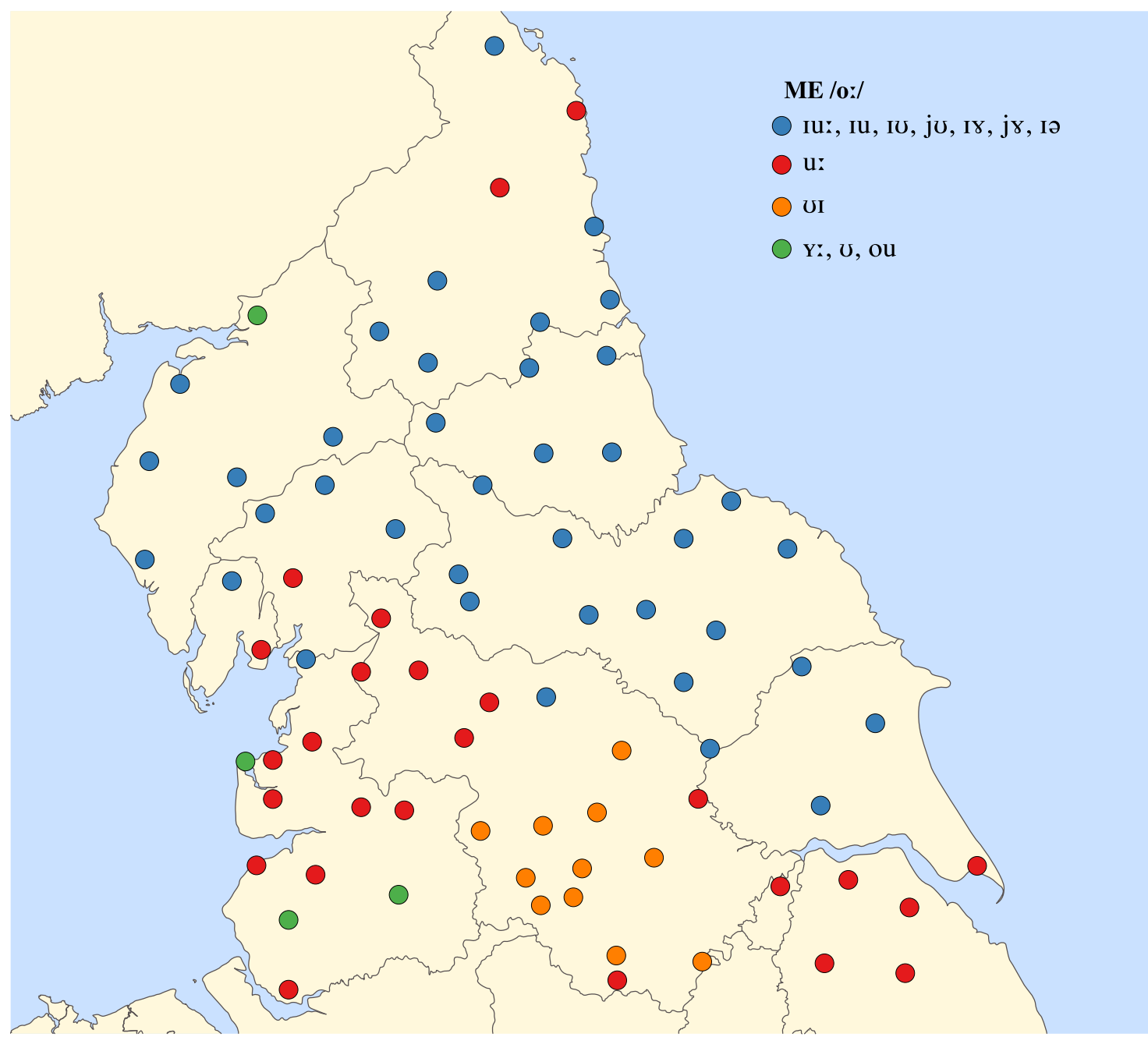

Map 8. Reflexes of ME $\bar{u}$.

which has long distinguished the dialects to the north and south.

The chronology for this vowel was as follows, in the areas in which it fronted: $\bar{o}$ fronted to [ø:], which was raised to [y:], and later diphthongized to [Iv] etc. Wells (1982:I.186) identifies these fronted variants as now "sharply recessive," an indication of which may be seen in the two Northumberland locales displaying a geographically-isolated (presumably levelled) [u:] reflex. Similarly, the [u:] reflexes found in North Lincolnshire are likely late developments owing to diffusion from the south, as argued in Britton 2002, and not a GVS-induced merger between ME $\bar{o}$ and $\bar{u}$.

This is the second vowel which is crucial to Luick's push-chain model, since it has been proposed that it was the fronting of $\bar{o}$ prior to the GVS which was responsible for the lack of diphthongization of $\bar{u}$ in parts of the north. The dependency relationship between these two vowels is examined more thoroughly in Section 4.3 below; for the moment, simply note that there are two different types of ME $\bar{o}$ reflex being shown here: One which underwent fronting, and one which did not. Based on this map (Map 8), there appears to be a reasonably clean divide along the RibbleHumber line (which agrees with Wells's description) between the two types of reflex, with no obvious transition zone.

The next two maps, Maps 9 and 10, show the reflexes of ME $\bar{\jmath}$. The lexical items all belong to the modern GOAT class: clothes, both, oak $\left(\bar{\jmath}_{1}\right)$, and coal, foal, note $\left(\bar{\jmath}_{2}\right)$; however, the two groups have quite distinct histories in the north. The first set, $\bar{\nu}_{1}$, belongs to the OE $\bar{a}$ class, which was raised and rounded to $\bar{\nu}$ in southern $\mathrm{ME}$, but remained unchanged in northern $\mathrm{ME}$, instead fronting and raising along with ME $\bar{a}$ (Mossé, 1952:22). The second set, $\bar{\nu}_{2}$, is derived from early ME $\breve{o}$ with OSL and remained back, generally developing into an ingliding diphthong. In the south then, both these classes were raised to [o:] by the GVS, after which [ou] merged into the class, which was later raised and diphthongized to 


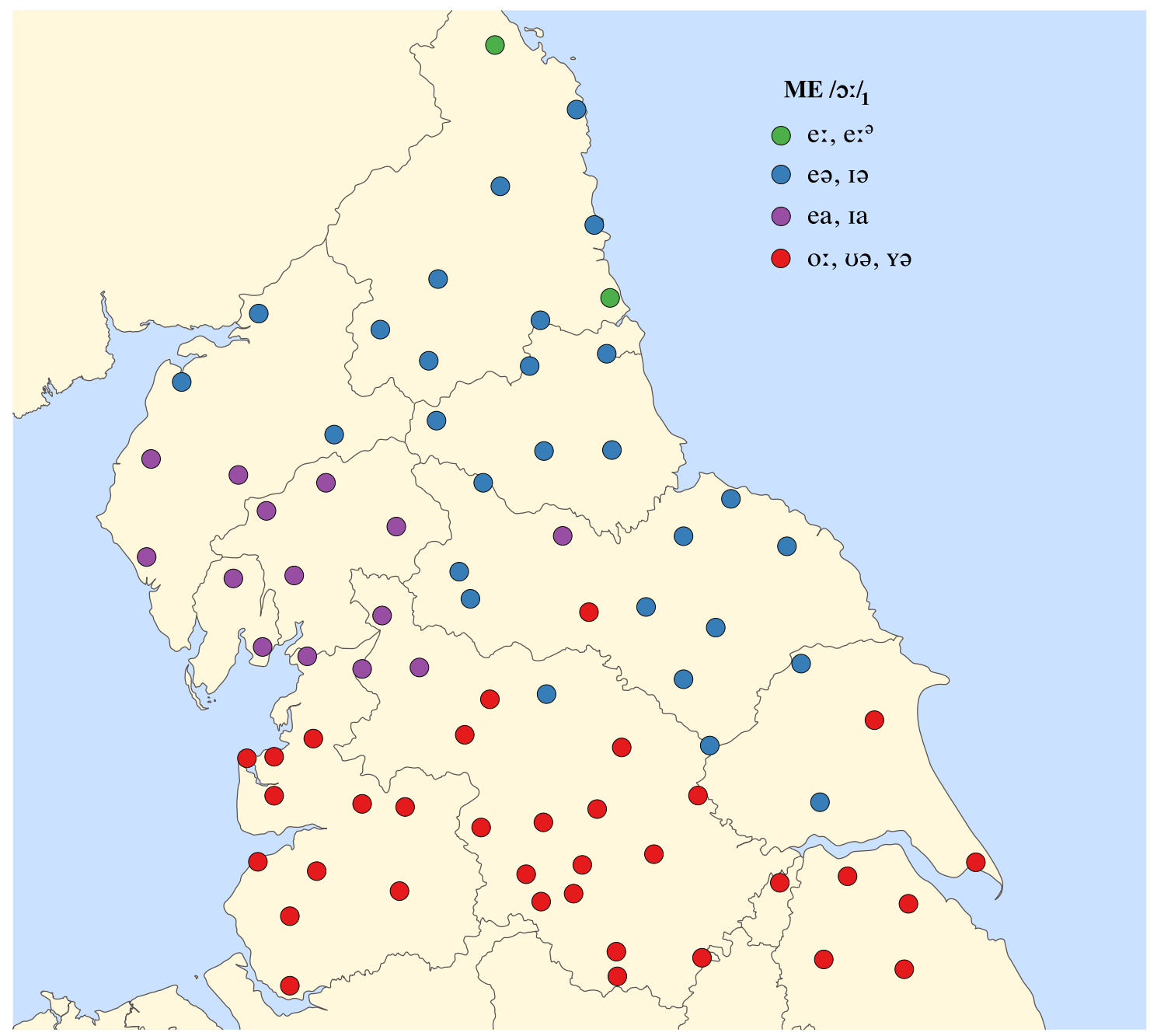

Map 9. Reflexes of ME $\bar{\jmath}_{1}$.

the modern reflex, [ov]. In the north, only the $\bar{\nu}_{2}$ class followed this path, while the $\bar{\nu}_{1}$ class remained fronted and later raised along the front track to [e:]. Modern monophthongal variants reflect a lack of the Long Mid Diphthonging change, and are generally found in the north (Wells, 1982:I.146).

The modern reflexes in Map 9 clearly display the distinct history of this vowel class in the north. North of the Ribble-Humber line we see reflexes with front nuclei; to the south, the nuclei remain back and show GVS raising, precisely the distinct outcomes expected. The $\bar{\jmath}_{2}$ class mapped in Map 10 shows a different pattern. The only fronted forms are found in Northumberland, in the Durham and Tyne and Wear area, and they are historically unrelated to the forms seen in Map 11. It is likely that these [ø: øə] reflexes represent a further innovation over the [və] reflexes found throughout most of the north, along the general lines suggested by Lass (1976:98ff.). Wales (2006:173) reports with some skepticism that Wakelin (1984) attributes this feature to "an attempt to 'conform more closely' to RP."

Whereas the northern front vowel system showed the expected reflexes of the GVS, including varying degrees of advancement of the shift which formed nesting patterns, the back vowel system shows far less influence of the GVS. Outside of southeast Lancashire and Yorkshire, there are very few of the expected GVS reflexes to be found. The only vowel which shows a clear nesting pattern is ME $\bar{u}$, and even then, only within the southwestern area which had not undergone prior $\bar{o}$-fronting; ${ }^{6}$ both $\bar{o}$ and $\bar{\jmath}$ present much more complex pictures, owing to their distinct histories in the north. Overall, the picture seems to be one of regular transmission within the southeastern locales which followed the south in raising rather than fronting $\bar{o}$ and $\bar{\nu}_{1}$; however, the GVS back-vowel changes could not be transmitted in the areas north of the Ribble-Humber line which had prior fronting of these vowels. 


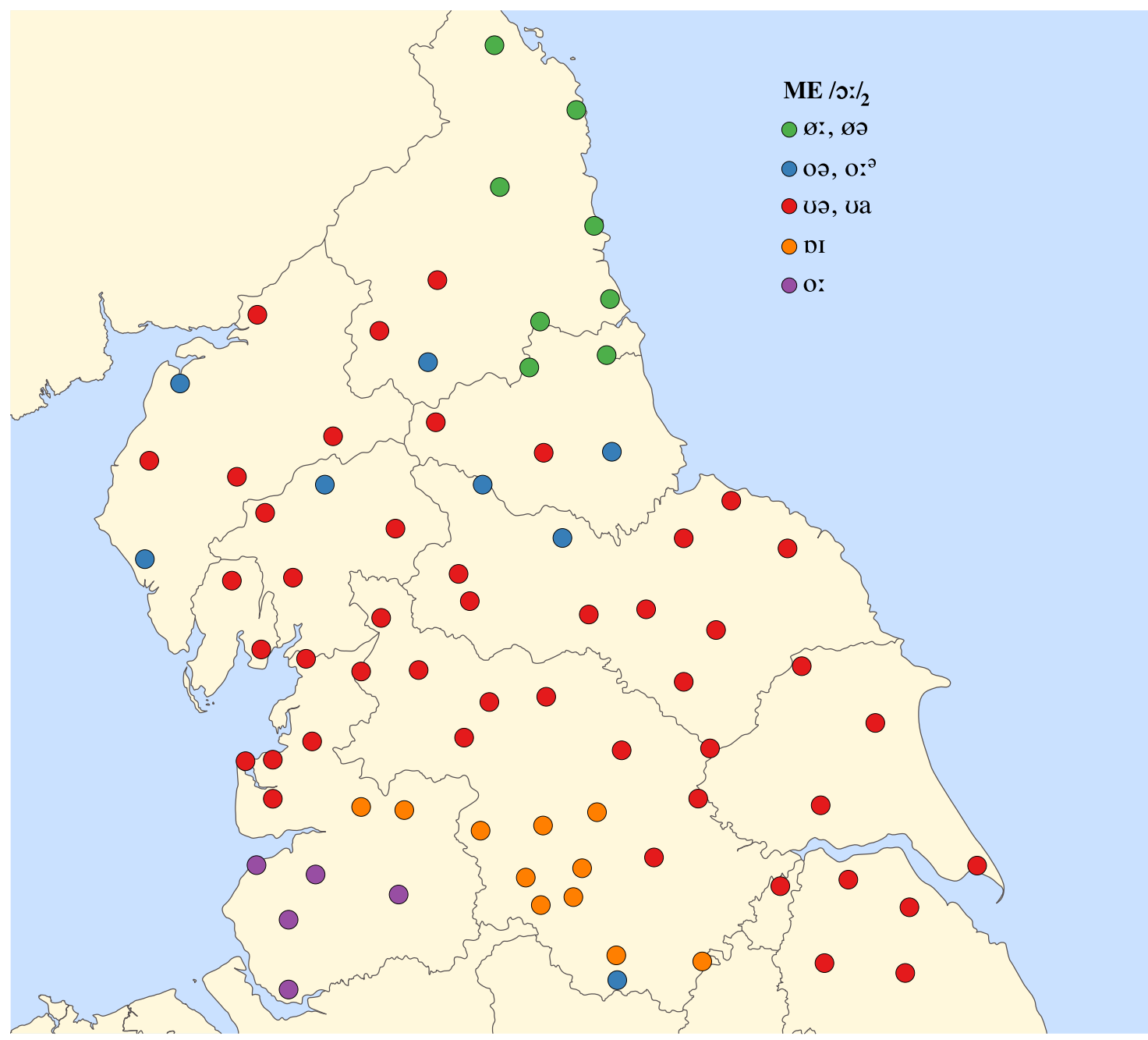

Map 10. Reflexes of ME $\bar{\jmath}_{2}$.

\subsection{Dependency Relationships}

The last map presented here returns to the question of the dependency relationship between $\bar{o}$-raising and $\bar{u}$-diphthongization upon which Luick's push-chain model relies. If his chronology is correct, and we assume that the GVS proceeded as a unitary shift in the north, then we might not expect to see any $\bar{u}$-diphthongization in the areas of the north in which $\bar{o}$-raising did not occur, due to prior $\bar{o}$-fronting. Given the possibility for diffusion, however, we expect that any locales which do show both $\bar{u}$ diphthongization and $\bar{o}$-fronting will be found in a transition zone where contact is likely between the dialects which fronted $\bar{o}$ and those which didn't.

As Map 11 shows, there is indeed a band running diagonally across the north where we see evidence of both $\bar{o}$-fronting and $\bar{u}$-diphthongization. ${ }^{7}$ Of this area, Anderson (1987:41) says,

It is hard to account for this intrusion [of $\bar{u}$-diphthongs] into an area which is generally highly conservative, and one can only assume that the change has been introduced from the Lancashire side or possibly from more southerly parts of the West Riding.

These apparently contradictory outcomes are precisely the sort of evidence that has been used by scholars in the past to argue against Luick's chronology, or the very unity of the shift itself (specifically Western, 1912:3).

However, the complete shifts of $\bar{l}$ and $\bar{e}$ in the front vowel system across the north as a whole, and the complete shifts of the back vowels in southeastern Lancashire and Yorkshire tend to support the coherence of the chain shift. The fact that these contradictory points are located along the Ribble-Humber line, rather than say the far north, agrees with the diffusion hypothesis stated above and suggests that these diphthongs may not be a separate, spontaneous development. ${ }^{8}$ I therefore interpret this data not as a refutation of Luick's theory, but as evidence that any standard GVS back vowel reflexes north of the 


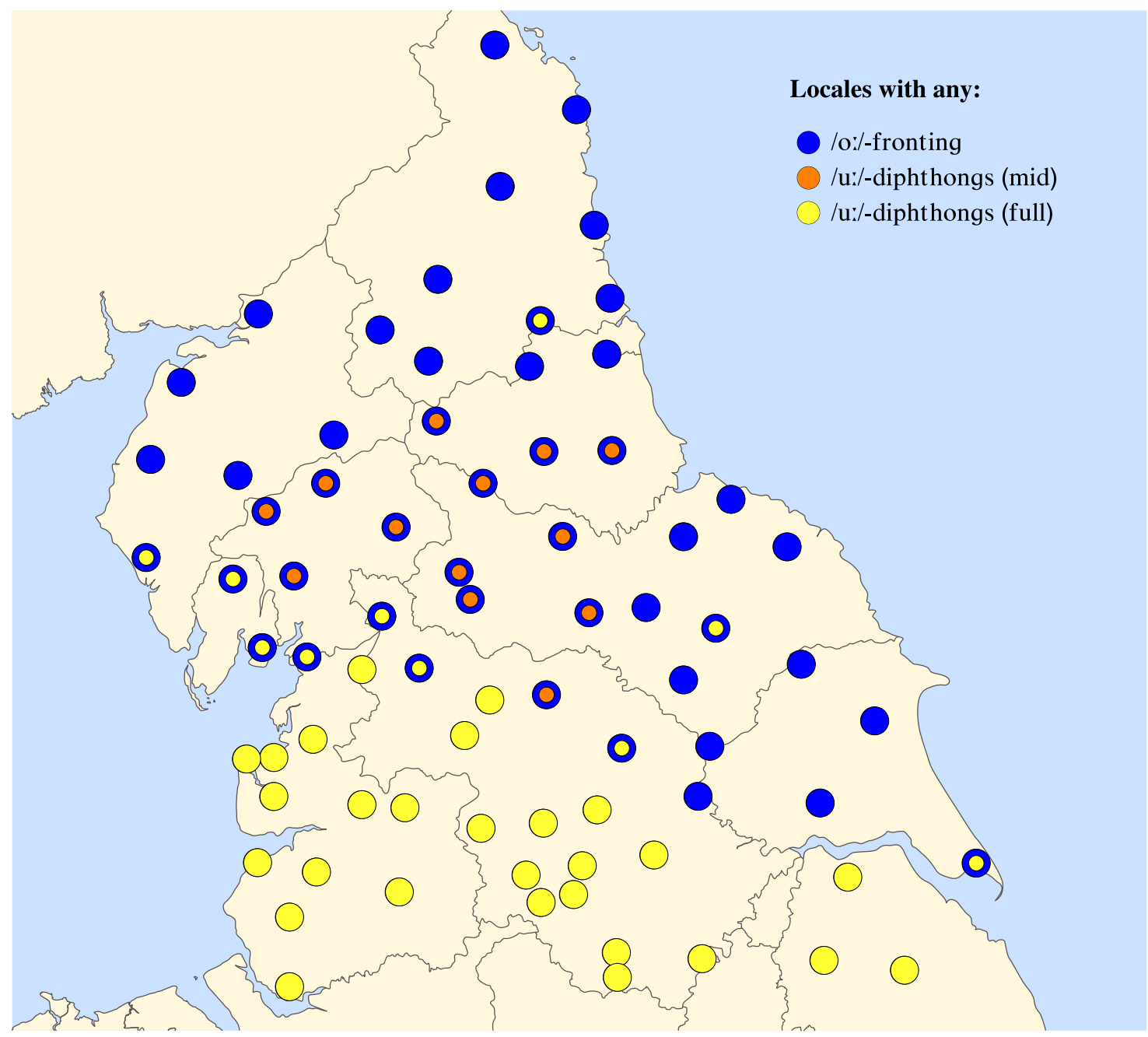

Map 11. Back vowel relationships.

Ribble-Humber line are the product of diffusion rather than regular transmission, which would have proceeded as a unitary chain shift. This analysis leads to the following rough sketch of the history of the GVS in the north:

(1) The GVS spread in a regular fashion across the north by means of transmission.

(2) The $\bar{o}$-raising change was not able to be transmitted north of the Ribble-Humber line, since $\bar{o}$ in that region had undergone prior fronting.

(3) Thus $\bar{u}$ also did not diphthongize in those locations since the condition for diphthongization ( $\bar{o}$-raising) was absent.

(4) Any apparently inconsistent modern data concerning these back vowels may be explained as the result of post-GVS diffusion, as I have demonstrated here for the cases where fronted $\bar{o}$ and diphthongized $\bar{u}$ coexist, and as Britton (2002) did for the areas in north Lincolnshire where both raised $\bar{o}$ and undiphthongized $\bar{u}$ can be found.
By viewing this data in the light of the transmission versus diffusion distinction, the apparent irregularities of the GVS in the back vowels of the north cease to be problematic for a unitary account of the GVS. Rather, these irregularities are seen as the natural result of the breakdown in structural relationships that occurred during the later diffusion of the back vowel changes from the south, across the dialect boundary running from the Ribble to the Humber.

In showing that these apparently contradictory reflexes are part of a larger pattern, and not truly random or problematic, this work demonstrates one way in which a new perspective may fruitfully contribute to a widely discussed question. While there are certain regular outcomes which are strong enough to appear even in a small subset of data, this analysis was naturally limited by the small amount of data used. Given only 2-5 words per vowel class, it was impossible to reliably observe the contextual effects which are known to affect the GVS, for example (e.g., those noted in 
Dobson, 1968). A useful extension of this project would be to similarly map all of the SED data, and perhaps some of the more reliable orthoepists' notes, in order to arrive at a more nuanced picture of the patterns of change present. It was also not feasible to conduct an exhaustive study of the available historical evidence here; some of this history is examined elsewhere (Prichard, to appear), but much more could be done to trace the history of some of the more unusual modern reflexes noted here.

\section{Conclusion}

Based on the findings above, this study concludes that the problematic nature of the ME long vowel reflexes in the north is simply the result of the diffusion of fully-shifted forms into an area which had a rather different initial vowel system than was found in the south. I therefore agree with Smith's (1996:99) assessment that although

the processes involved in the Northern Shift are useful for our understanding of the process of triggering of the wider Shift, it is suggested here that the problem presented by these dialects is distinct from that manifested by the more southerly varieties

but disagree with his conclusion that these problems are best accounted for by postulating a separate northern shift. This analysis accounts for the fact that regular outcomes and nesting patterns are found for the reflexes of the front vowels, while irregular outcomes and diffusion patterns are found for the back vowels: The prior fronting of $\bar{o}$ in the north prevented the GVS from occurring in the back vowels, even as it proceeded regularly in the front vowels. The back vowel outcomes which appear to be the result of the GVS are the result of diffusion from areas which did undergo the full shift.

\section{Acknowledgements}

Thanks to Bill Labov, Don Ringe, Gillian Sankoff, Kyle Gorman, and audiences at NEW5 and NWAV41 for their helpful comments; to Aaron Ecay and Chris Montgomery for their contributions to the maps presented here; and to an anonymous reviewer especially for the time and effort they devoted to furthering my education in the historical intricacies of the Northern English dialects. This work is based on data provided through EDINA UKBORDERS with the support of the ESRC and JISC and uses Kain and Oliver historic boundary material which is copyright of the AHDS History [University of Essex], Humphrey Southall, Nick Burton and the University of Portsmouth.

\section{Notes}

1 'Irregular', in the sense of unexpected, not the result of regular application of the GVS changes.
$2 \quad$ Further discussion of these arguments and a more detailed history of Northern English vowels may be found in Prichard (to appear).

3 Obsolete IPA characters have been replaced with their modern equivalents here.

4 To use the tooltip function, you must view the maps in a web browser, either by downloading the accompanying svg files, or by viewing the html version of this article.

5 I know of two possible exceptions to this consensus: Johnston (1992), who proposes a northern/midlands origin (but argues that the GVS is really two unrelated shifts), and Smith (2007), who similarly proposes that the northern vowel changes are completely separate from those that occurred in the south.

6 As a reviewer points out, Lass (1976:89) suggests that even these diphthongal reflexes of ME $\bar{u}$ may be 'late importations'. However, as he does not specify how late, it is difficult to know if these are best seen as recently-levelled varieties, or areas in which the shift was very slowly transmitted.

7 The area of diphthongization shown in Map 11 is not identical to that seen in Map 7. Since it is argued here that the diphthong is diffusing from the south, and this may of course proceed by means of lexical diffusion, Map 11 assumes that locations which reported a diphthong in any ME $\bar{u}$ word, even if a majority of the data did not have a diphthong, provide evidence for the diffusion of the standard form.

8 That said, in Map 11 I have differentiated "full" diphthongs (the [av] type) from "mid" diphthongs (the [ov] type) as it is not clear that these are both the product of diffusion. The history of the mid diphthongs will need to be investigated elsewhere.

\section{References}

Anderson, Peter M. 1987. A structural atlas of the English Dialects. London: Croom Helm.

Beal, Joan C. 2010. An introduction to regional Englishes: Dialect variation in England. Edinburgh: Edinburgh University Press.

Boisson, Claude. 1982. Remarques sur la chronologie interne du grand changement vocalique en anglais. Apports français à la linguistique anglaise. Travaux 35, CIEREC, Université de Saint-Etienne.

Britton, Derek. 2002. Northern fronting and the north Lincolnshire merger of the reflexes of ME / $\mathrm{u}$ // and ME /o:/. Language Sciences 24. 221-229.

Carter, Richard. 1975. Some theoretical implications of the Great Vowel Shift. In Didier L. Goyvaerts \& Geoffrey K. Pullum (eds.), Essays on the sound pattern of English, 369-376. Ghent: Story Scientia.

Chomsky, Noam \& Morris Halle. 1968. The sound pattern of English. New York: Harper \& Row.

Cooper, Christopher. 1685. Grammatica Linguae Anglicanae. Quoted in Dobson, E. J. 1968. English pronunciation 1500-1700, vol. 2, 2nd edn. London: Oxford University Press.

Dinkin, Aaron. 2012. Toward a unified theory of chain shifting. In Terttu Nevalainen \& Elizabeth C. Traugott (eds.), 
The Oxford handbook of the history of English, 748-760. Oxford: Oxford University Press.

Dobson, E. J. 1968. English pronunciation 1500-1700, vol. 2, 2nd edn. London: Oxford University Press.

Gil, Alexander. 1619. Logonomia Anglica. Quoted in Dobson, E. J. 1968. English pronunciation 1500-1700, vol. 2, 2nd edn. London: Oxford University Press.

Jespersen, Otto. 1909. A modern English grammar on historical principles, vol.1: Sounds and spellings. Copenhagen: Munksgaard.

Johnston, Paul A. 1992. English vowel shifting: One Great Vowel Shift or two small vowel shifts? Diachronica, 9(2). 189-226.

Kerswill, Paul. 2003. Dialect levelling and geographical diffusion in British English. In David Britain \& Jenny Cheshire (eds.), Social dialectology: In honour of Peter Trudgill, 223-243. Amsterdam: Benjamins.

Kolb, Eduard. 1966. Linguistic atlas of England. Phonological atlas of the Northern region. Bern: Francke.

Labov, William. 1994. Principles of linguistic change, vol. 1: Internal factors (Language in Society 20). Cambridge, MA: Blackwell.

Labov, William. 2007. Transmission and diffusion. Language 83. 344-387.

Labov, William, Sharon Ash \& Charles Boberg. 2006. The atlas of North American English. Berlin: Mouton de Gruyter.

Lass, Roger. 1976. English phonology and phonological theory: Synchronic and diachronic studies. Cambridge: Cambridge University Press.

Lass, Roger. 1992. What, if anything, was the Great Vowel Shift? In Matti Rissanen, Ossi Ihalainen, Terttu Nevalainen, \& Irma Taavitsainen (eds.), History of Englishes: New methods and interpretations in historical linguistics, 144-155. Berlin: Mouton de Gruyter.

Luick, Karl. 1896. Untersuchungen zur englischen Lautgeschichte. Straßburg: Trübner.

Milroy, James. 1996. Variation in /ai/ in Northern British English, with comments on Canadian Raising.
University of Pennsylvania Working Papers in Linguistics 3(1). 213-221.

Montgomery, Chris. 2007. Northern English dialects: A perceptual approach. Sheffield, UK: University of Sheffield doctoral thesis.

Mossé, Fernand. 1952. A handbook of Middle English. Baltimore: The Johns Hopkins Press.

Ogura, Mieko. 1987. Historical English phonology. Tokyo: Kenkyusha.

Orton, Harold. 1962. Survey of English dialects (A), vol. 1: Introduction. Leeds: E. J. Arnold \& Son.

Prichard, Hilary. to appear 2014. Northern English and historical phonology. In Raymond Hickey (ed.), Researching Northern English. Amsterdam: John Benjamins.

Smith, Jeremy. 1996. An historical study of English: Function, form and change. London: Routledge.

Smith, Jeremy. 2007. Sound change and the history of English. Oxford: Oxford University Press.

Smith, Thomas. 1568. De recta et emendata linguæ anglicæ scriptione, Dialogus. Quoted in Dobson, E. J. 1968. English pronunciation 1500-1700, vol. 2, 2nd edn. London: Oxford University Press.

Stockwell, Robert \& Donka Minkova. 1988. The English Vowel Shift: problems of coherence and explanation. In Dieter Kastovsky \& Gero Bauer (eds.), Luick revisited: Papers read at the Luick Symposium at Schloß Liechtenstein, 1985, 355-394. Tübingen: Gunter Narr Verlag.

Wakelin, Martyn. 1984. Rural dialects in England. In Peter Trudgill (ed.), Language in the British Isles, 70-93. Cambridge: Cambridge University Press.

Wales, Katie. 2006. Northern English: A social and cultural history. Cambridge: Cambridge University Press.

Wells, John C. 1982. Accents of English, vols. 1-3. Cambridge: Cambridge University Press.

Western, August. 1912. Über die neuenglische Vokalverschiebung. Englische Studien, 45. 1-8. 